\title{
O Recrutamento Interno e sua Relação com o Desenvolvimento Profissional e Retenção de Talentos
}

\author{
Sergio Santoro ${ }^{1}$
}

\begin{abstract}
Resumo
Esta pesquisa trata sobre o Processo de Recrutamento e Seleção, priorizando o recrutamento interno. Além disso, procura relacionar o recrutamento interno com o desenvolvimento profissional, investigando sua contribuição para manter pessoas com potencial e talento dentro das empresas por mais tempo. Para isto, realizou-se uma pesquisa exploratória, com abordagem dos dados predominantemente quantitativa, por meio de dois questionários, sendo o primeiro destinado para profissionais de diferentes áreas de atuação, e o segundo para profissionais da área de Recursos Humanos. Em linhas gerais, os resultados sugerem que o recrutamento interno pode proporcionar chances para que todos os colaboradores concorram às oportunidades que surgem na empresa, assumindo um papel relevante na identificação de talentos já existentes na organização e de orientação de carreira, desde que realizado de forma transparente, imparcial e contínua pelos profissionais de Recursos Humanos.
\end{abstract}

Palavras-chave: recrutamento e seleção, recrutamento interno, gestão de carreira, desenvolvimento de pessoas.

\begin{abstract}
This research deals with the Recruitment and Selection Process, giving priority to the Internal Recruitment. Moreover, it attempts to relate the Internal Recruitment with professional development, investigating its contribution to keeping people with potential and talent inside companies for a longer period of time. To do so, an exploratory research was carried out, with a predominantly quantitative data approach, through two questionnaires, one intended for professionals from different areas, and the second for professionals from the Human Resources area. Generally speaking, the results suggest that the Internal Recruitment can provide chances for all employees so that they can compete for job opportunities in the company they already work for, assuming an important role in identifying existing talented people in the company and career guidance, since it is performed in a transparent, impartial and continuous way by Human Resources professionals.

Keywords: recruitment and selection, internal recruitment, career management, people development.
\end{abstract}

\section{INTRODUÇÃO}

A área de Recursos Humanos deve estar intimamente relacionada com os objetivos e metas de uma organização empresarial, oferecendo suporte para todas as demais áreas, contribuindo para um maior engajamento de todos os colaboradores. Uma das demandas

\footnotetext{
${ }^{1}$ Mestre em Administração de Empresas pela Universidade Presbiteriana Mackenzie e Doutorando em Gestão de Empresas pela Universidade de Coimbra/Portugal. sergio_santoro@hotmail.com
} 
principais de Recursos Humanos no cenário atual do mundo corporativo é atrair, desenvolver e reter profissionais que possam fazer a diferença. Este desafio começa, portanto, com a atração de profissionais qualificados no mercado de trabalho, isto é, com o Processo de Recrutamento e Seleção.

Os profissionais que estão no mercado de trabalho vêm se tornando cada vez mais exigentes nas escolhas referentes à empresa para a qual gostariam de se candidatar a uma vaga de emprego. O salário, contudo, não é mais o único atrativo para captar e reter um profissional. Podemos incluir além de um bom salário, os benefícios oferecidos e, um ponto de fundamental relevância nesta tomada de decisão, que é a possibilidade de crescimento dentro da empresa (GIANI, 2011).

De acordo com Giani (2011), a grande maioria das organizações acaba perdendo seus talentos por não possuírem ou não divulgarem de forma transparente uma política interna de carreira, como as práticas de mercado têm nos mostrado, pois no momento de contratar, perde-se um tempo precioso procurando no mercado externo um profissional que esteja dentro de um perfil desejado.

Os tipos de cargos que as empresas precisam preencher mudam frequentemente, pois há fatores internos e ambientais que exercem influência sobre eles. Por sua vez, a capacidade das pessoas e suas aspirações pessoais também se transformam ao longo do tempo, como resultado de eventos relacionados ao trabalho e à vida pessoal.

A atividade de Recrutamento e Seleção pode ser considerada estratégica, pois representa uma área de contribuição direta aos resultados globais de uma organização e é a porta de entrada para os profissionais que vão fazer parte dela. A empresa, portanto, deve ser um local inspirador para os profissionais de talento e para o mercado. Organizações que conseguem firmar uma boa imagem como empregadoras têm mais facilidade de atrair e, fundamentalmente, de reter talentos em seus quadros. O planejamento de pessoal deve estar em sintonia com a estratégia de negócios da organização, para que a atividade de recrutamento possa atuar de forma preventiva. Quando esses dois pontos estão em harmonia planejamento adequado e boa reputação no mercado - o profissional de recrutamento e seleção pode exercer uma função estratégica, evitando que a atividade esteja sempre em débito e focada no operacional.

Para se atingir qualquer objetivo organizacional, o capital humano é fator primordial e indispensável (GUIMARÃES, 2005). Portanto, para que uma empresa seja bem-sucedida no mercado competitivo atual, ter as pessoas corretas e mais bem preparadas nas suas funções, 
além de reter seus talentos por mais tempo, pode ser estrategicamente vital para a saúde de uma organização.

O principal desafio é como aprimorar o Processo de Recrutamento e Seleção, sobretudo como o Recrutamento Interno pode se tornar fator motivacional preponderante para que a empresa possa ter colaboradores com maior grau de qualificação, treinados e comprometidos com a organização, contribuindo para a diminuição da rotatividade de pessoas e consequente retenção de talentos em seus quadros.

Este trabalho aborda o tema do Processo de Recrutamento e Seleção, com ênfase no Recrutamento Interno como gerador de desenvolvimento profissional, e como ele pode contribuir para a diminuição da rotatividade de pessoal nas organizações modernas.

\section{RECRUTAMENTO E SELEÇÃO}

O mundo atual dos negócios é caracterizado por um ritmo frenético e uma concorrência forte e perspicaz. O sucesso das empresas, invariavelmente, dependerá do talento dos seus recursos humanos. Existem empresas que se diferenciam por acreditarem verdadeiramente na importância das pessoas, buscando encontrar os colaboradores certos para cada função, fazendo com que estes permaneçam por mais tempo em seu quadro funcional, agregando valor e conhecimento à organização. Quando falamos de Recrutamento e Seleção, estamos nos referindo a uma das mais importantes ferramentas de gestão de pessoas nas organizações modernas.

\subsection{O Recrutamento}

O recrutamento consiste num conjunto de técnicas e procedimentos que tem por objetivo atrair candidatos potencialmente qualificados, internos ou externos, capazes de ocupar cargos, para atender as demandas atuais e futuras dentro de uma organização.

O recrutamento funciona como um processo de comunicação, na medida em que a empresa divulga e oferece oportunidades de trabalho no mercado. Assim como ocorre com o processo de comunicação, o recrutamento é uma "via de mão-dupla": ao mesmo tempo em que comunica e divulga oportunidades de emprego, atrai candidatos para o processo seletivo.

Através do processo de recrutamento, a empresa divulga ao mercado de trabalho que existem oportunidades de emprego para determinadas funções. Para que o processo de recrutamento se inicie, é fundamental que a organização tenha a necessidade de contratar pessoas para desempenhar funções específicas, determinando qual o perfil de competências - 
conjunto de conhecimento, habilidades e atitudes - que interessa encontrar, tendo em vista seus objetivos estratégicos e operacionais. Esta clara definição possibilitará maior sucesso na tentativa de buscar o profissional mais adequado, evitando-se, assim, erros que podem comprometer a empresa mais tarde.

O recrutamento interno acontece quando surge uma vaga na organização e esta procura preenchê-la através do remanejamento de seus empregados, que podem ser transferidos, promovidos, ou as duas coisas (GIANI, 2011). O recrutamento pode ser interno, quando atua sobre os candidatos que estão trabalhando dentro da organização, com o objetivo de promovê-los ou transferi-los para outras atividades mais complexas ou mais motivadoras. Para Chiavenato (2006), o recrutamento interno "aproveita melhor o potencial humano da organização, motiva e encoraja o desenvolvimento profissional dos atuais funcionários, incentiva a permanência e fidelidade dos funcionários na organização, aumenta a probabilidade de uma melhor seleção, pois os candidatos são bem conhecidos, e custa financeiramente menos do que fazer recrutamento externo". Outra vantagem do recrutamento interno, é que ele apresenta um índice de validade e segurança bem maior do que o recrutamento externo, pois, além do empregado já ser conhecido na empresa, pode gerar uma motivação maior para todos os empregados. Uma desvantagem desse tipo de recrutamento é o fato de haver uma maior exigência e condições dos empregados, para poderem exercer as funções de um determinado cargo que, por vezes, ainda não estão aptos para isso.

Ainda segundo Giani (2011), para que o recrutamento interno seja constante e justo é preciso que se considere a avaliação de desempenho e/ou a avaliação de potencial de seus funcionários. A primeira mede os resultados de trabalho em função das responsabilidades do cargo, enquanto que a segunda procura identificar no colaborador qualificações, requisitos e aptidões exigidos pelo cargo. Ademais, outros dados são levados em conta: resultados obtidos na sua avaliação de ingresso na organização; resultados obtidos em treinamentos internos; análise do cargo atual e do cargo pretendido; planos de carreira e condições de promoção do candidato interno e se já existe um outro substituto para seu lugar.

Já o recrutamento externo, para Chiavenato (2006), é um conjunto de atividades que visam atrair um conjunto de candidatos qualificados, que estão espalhados no mercado, ou seja, fora da organização, e que se submeterão ao Processo de Seleção de Pessoal, a fim de ingressarem na organização. $\mathrm{O}$ processo de recrutamento externo incide sobre pessoas com potencial, disponíveis ou empregadas em outra organização. Algumas vantagens do recrutamento externo são: novas experiências para a empresa; renova os recursos humanos da organização; aumenta o capital intelectual; aproveita os investimentos em preparação e o 
desenvolvimento de pessoal efetuado por outras empresas ou pelos próprios candidatos. Por outro lado, as principais desvantagens são: um processo mais demorado do que o recrutamento interno; mais caro, exigindo inversões e despesas imediatas com anúncios, jornais, honorários de agências de recrutamento; e menos seguro do que o recrutamento interno (desconhecimento mútuo: empresa e candidato).

Uma organização raramente faz apenas um recrutamento interno ou externo, pois ambos são complementares. A partir do momento em que o recrutamento interno se dá, em algum lugar da organização haverá uma posição que poderá ser preenchida através do recrutamento externo ou outro recrutamento interno.

O processo de recrutamento conta atualmente com diversas fontes, de acordo com o tipo de profissional, a confidencialidade do processo, os recursos disponíveis e a urgência. As fontes mais amplamente usadas são: cadastro próprio no portal da organização por procura espontânea ou indicações; universidades conveniadas e/ou escolas técnicas profissionalizantes; entidades de classe, associações e grupos informais; anúncios em geral; consultorias especializadas em transição de carreiras; empresas especializadas em recrutamento e seleção; e internet. Essa última fez com que os processos de recrutamento e seleção ganhassem nova dinâmica.

\subsection{A Seleção}

Após o recrutamento e triagem dos candidatos, o próximo passo é a seleção. É pressuposto do processo de seleção fazer uma comparação e, consequentemente, uma escolha. A comparação se dá pelas características de cada candidato com o padrão de referência que são as especificações do cargo. As especificações são advindas da descrição do cargo a ser preenchido e definem o que o cargo requer do seu ocupante. Finalizada a comparação, há a possibilidade de haver vários candidatos adequados ao cargo. A escolha, então, sobrevém. A seleção de pessoal é basicamente comparativa e restritiva.

Dessler (2003, p. 106) fala da importância de selecionar os candidatos certos para preencher as vagas na organização.

Selecionar os funcionários certos é importante por três razões principais: o seu próprio desempenho depende, em parte, dos seus funcionários; funcionários com boas habilidades e atributos farão um trabalho melhor para você e para a empresa; funcionários que não tenham essas habilidades e atributos, que causem atritos ou criem dificuldades não terão um desempenho efetivo e prejudicarão o seu próprio desempenho e o da empresa. A hora de separar os indesejáveis é antes de eles entrarem pela porta, não depois. 
A escolha do candidato certo para o desempenho das funções que irá exercer na empresa será fundamental para a organização alcançar o sucesso. "A seleção busca entre os candidatos recrutados aqueles mais adequados aos cargos existentes na empresa, visando a manter ou aumentar a eficiência e o desempenho do pessoal, bem como a eficácia da organização" (CHIAVENATO, 1999, p. 233).

De acordo com Chiavenato (2006), a seleção de recursos humanos por ser um sistema de comparação e de escolha, deve apoiar-se em algum padrão ou critério para ter validade. $\mathrm{O}$ padrão ou critério é obtido a partir das características do cargo a ser preenchido. Dessa maneira, a base para a seleção é a obtenção de informações para o cargo.

As informações sobre o cargo a ser preenchido podem ser classificadas em cinco grupos, conforme Chiavenato (2006):

- Entrevistas: é a ferramenta mais importante do processo de seleção, e por isso, deve ser feita por um profissional experiente e que identifique que fatores de ordem pessoal podem interferir no processo (antipatia, atração, rejeição etc.). Recomenda-se que vários entrevistadores avaliem o mesmo candidato para reduzir este problema;

- Provas de Conhecimento: podem ser gerais ou específicas. As provas gerais procuram identificar o grau de cultura geral do candidato. Essas provas têm baixa correlação com o desempenho profissional imediato, mas servem para compreender melhor o universo do candidato e sua atitude pessoal/profissional. As provas específicas procuram avaliar os conhecimentos profissionais que o candidato possui indispensáveis para o bom desempenho da função;

- Testes Psicológicos: são instrumentos padronizados que estimulam determinado comportamento do examinado. Servem para predizer o comportamento humano baseado no que o teste revelou;

- Técnicas Vivenciais: exigem respostas a situações de modo que os candidatos interajam e participem ativamente delas;

- Avaliação de Saúde: o médico deve conhecer a função para avaliar as condições de saúde do candidato e verificar se ele está ou não apto para o desempenho da função.

O papel do selecionador é identificar o perfil de competências técnicas e comportamentais que o cargo precisa e obter as ferramentas para aplicar nos candidatos e identificar qual, entre todos eles, tem o perfil mais compatível com a necessidade do cargo. 


\section{GESTÃO DE CARREIRA}

A retenção de profissionais talentosos é um constante desafio para as empresas que querem se manter competitivas. Para tanto, elas precisam criar ferramentas para identificar esses profissionais e, principalmente, desenvolver programas para a sua retenção.

O conceito de carreira transformou-se com a evolução das teorias de administração e o contexto de nossas relações sociais. Houve uma mudança da concepção de carreira voltada para a empresa para uma concepção mais individualizada, portanto, o conceito de carreira baseia-se, sobretudo, no indivíduo e nas suas necessidades (COSTA; DUTRA, 2011). Entende-se o desenvolvimento de carreira como um processo de avaliação, alinhamento e conciliação entre as necessidades, oportunidades e mudanças organizacionais e individuais, através do recurso a múltiplas abordagens e metodologias (JACKSON, 2000).

O desenvolvimento de carreiras permite que o próprio colaborador e a empresa possam conhecer melhor as características do colaborador e os seus interesses, além disso, propicia um melhor conhecimento sobre as opções e carreira do colaborador, para que as competências dos indivíduos possam se desenvolver e se concretize uma gestão do mercado interno em consonância com as necessidades da empresa e com a cultura organizacional.

A Gestão de Recursos Humanos pode assumir diferentes propostas na concepção, implementação e manutenção de um sistema de desenvolvimento de carreiras: um papel mais estratégico ou um papel que dá importância à formalização, assumindo-se simplesmente como gestão administrativa. Neste último caso, as promoções automáticas prevalecem e estão normalmente definidas nos contratos coletivos de trabalho, com base na antiguidade do colaborador da empresa. Caso assuma um papel mais estratégico, pretende-se: alinhar as expectativas dos colaboradores com a estratégia da organização; desenvolver os colaboradores com vista à sua promoção; diminuir os níveis de rotatividade (o interesse da empresa sobre as carreiras individuais dos colaboradores pode gerar mais lealdade e envolvimento para com a empresa, diminuindo o turnover); promover o potencial dos colaboradores, fato que pode aumentar a motivação e melhorar o desempenho nos cargos atuais; promover a mobilidade interna, que leva a uma distribuição mais estratégica dos indivíduos pela empresa; promover a mobilidade internacional, auxiliando a identificar ou a preparar a alocação de colaboradores em cargos no estrangeiro.

Ainda segundo Jackson (2000), existe um conjunto de atividades ou métodos em termos de desenvolvimento de carreiras, que podem variar em abordagem: 
- Formal vs. Informal: no primeiro caso é possível identificar os centros de desenvolvimento em termos de carreira, enquanto que no segundo caso, o encorajamento à autogestão individual das carreiras;

- Centralização vs. Descentralização: encontram-se métodos como os planos de sucessão que são organizados centralmente, enquanto outros, como coaching são organizados, sobretudo, ao nível mais local;

- Perfil dos colaboradores: algumas organizações decidem que os programas de desenvolvimento de carreiras devem aplicar-se a todos os colaboradores enquanto outras escolhem apenas um segmento deste grupo, caso dos quadros superiores ou dos colaboradores com um vínculo efetivo à organização.

A autogestão da carreira é interessante para o gestor organizacional na medida em que uma postura mais inovadora e empreendedora é esperada, que são características procuradas e estimuladas nas empresas. Além disso, há uma cobrança social sobre as pessoas para desenvolverem esta postura, pela ideia de que a pessoa pode e deve influenciar a sua própria trajetória e a valorização social do contínuo crescimento, da mobilidade, da flexibilidade e da notoriedade (DUTRA, 1996).

Segundo Dutra (1996), o indivíduo deve desenvolver três tarefas para o seu planejamento de carreira: a autoavaliação (qualidades, interesses e potencial); estabelecimento de objetivos de carreira (baseado na autoavaliação e nas oportunidades oferecidas) e implementação do plano de carreira (obtenção de capacitação e acesso às experiências profissionais necessárias).

Um bom sistema de carreiras deve estar assentado em princípios que representem os compromissos acertados entre a empresa e as pessoas, segundo Dutra (2002). O autor indica três instrumentos de gestão:

1. Decisões individuais sobre a carreira (na empresa ou não), com auto avaliação, processos de aconselhamento profissional, informações estruturadas sobre oportunidades profissionais internas e externas, processos estruturados de feedback, dentre outras.

2. Gerenciamento da carreira pela empresa, com previsões de demanda, programas de desenvolvimento, programas de captação interna e processos de acompanhamento do desempenho e crescimento profissional etc.. 
3. Comunicação entre as pessoas e a empresa, com programas de preparação e aperfeiçoamento dos gestores como conselheiros e orientadores, processos de negociação de objetivos de carreira e desenvolvimento etc..

O papel das empresas na gestão de carreiras envolve a criação de espaço, o estímulo ao desenvolvimento e o apoio e condições de progresso, através da contínua interação, respeito à individualidade, desenvolvimento e satisfação das pessoas e uma proposta clara de intenções (VELOSO; SCHIRMEISTER; LIMONGI-FRANÇA, 2007; COSTA; CHIUZI; DUTRA, 2013).

Com relação às pessoas, o papel baseia-se na gestão de seu desenvolvimento, da busca constante pela competitividade e da sua carreira, através do autoconhecimento e do conhecimento das oportunidades (VELOSO; SCHIRMEISTER; LIMONGI-FRANÇA, 2007).

\section{METODOLOGIA}

Do ponto de vista de seus objetivos, esta pesquisa é exploratória, pois visa proporcionar maior familiaridade com o problema com vistas a torná-lo explícito ou a construir hipóteses. O trabalho envolve levantamento bibliográfico; questionários e entrevistas com pessoas que tiveram experiências práticas com o problema pesquisado, assumindo a forma de Pesquisa de Campo. Do ponto de vista da forma de abordagem do problema, este trabalho emprega uma pesquisa quantitativa, pois considera aquilo que pode ser quantificável, traduzindo em números opiniões e informações para classificá-las e analisálas.

Para tanto, dois questionários foram elaborados. O primeiro questionário segue como modelo a escala de Likert, que possui cinco tipos de escolhas. Esta escala é usada como referência para vários trabalhos por aferir melhor os dados coletados. Tal questionário é geral, ou seja, seu público-alvo é formado por profissionais de diferentes áreas. Já o segundo questionário utiliza perguntas abertas para propiciar uma entrevista com profissionais da área de Recursos Humanos somente.

Para o primeiro questionário foi enviada uma mensagem eletrônica (e-mail) para 75 pessoas, que foram instruídas que aqueles dados seriam aplicados em um estudo universitário sobre o tema Recrutamento Interno como gerador de satisfação no trabalho e como ele pode contribuir para a diminuição da rotatividade de pessoal nas organizações modernas, e que o material preenchido fosse devolvido eletronicamente em até 20 dias. O questionário foi devidamente respondido por 45 profissionais de empresas das mais variadas áreas de atuação, 
da cidade de São Paulo e região metropolitana, no mês de novembro de 2015. O segundo questionário foi usado para entrevistar 5 profissionais de Recursos Humanos apenas, já considerando o universo de 45 respondentes do primeiro questionário, de empresas de diferentes setores da economia, da cidade de São Paulo e região metropolitana, no mês de novembro de 2015.

Após o recolhimento dos questionários respondidos, foi feita a tabulação de dados no programa Google Docs (Formulários), para que tabelas pudessem ser criadas para melhor exposição e comparação dos resultados aferidos.

\section{RESULTADOS E DISCUSSÃO}

A presente seção consta de cinco partes, nas quais foram analisados os resultados da pesquisa, provenientes do questionário enviado via mensagem eletrônica para profissionais das mais variadas áreas de atuação, e do questionário utilizado para entrevistar profissionais da área de Recursos Humanos somente.

Os resultados obtidos são apresentados nesta ordem: em primeiro lugar, os dados dos participantes da pesquisa; em seguida, os dados referentes à percepção do processo de recrutamento interno e seus critérios; depois, os fatores de sucesso ou inibidores para o processo de recrutamento interno; a percepção do processo de recrutamento interno como gerador de satisfação no ambiente de trabalho; e, finalmente, os dados sobre a percepção do processo de recrutamento interno como fator preponderante na gestão de carreira.

\section{a. Dados dos Participantes}

Pôde-se observar que, do total de participantes da pesquisa, 53\% são do sexo masculino e que $47 \%$, do sexo feminino.

Com relação à faixa etária dos participantes, observou-se que a média de idade está na faixa entre 26 e 35 anos, ou seja, $49 \%$ de todos os respondentes. Entre 18 e 25 anos, 16\%; entre 36 e 45 anos, $27 \%$; e com mais de 45 anos, $9 \%$.

Quando inquiridos a respeito do grau de escolaridade, 56\% (25) dos participantes responderam possuir Pós-graduação; e 44\% (20) dos respondentes afirmaram ter Ensino Superior.

Em se tratando do tempo total de serviço na empresa, $42 \%$ (19) da amostra disseram estar na mesma organização há mais de 5 anos; entre 3 e 5 anos, 22\% (10); entre 1 e 3 anos,

ReFAE - Revista da Faculdade de Administração e Economia, v. 8, n. 2, p. 37-59, 2017 
18\% (8); e igual percentual para aqueles que continuam a trabalhar na mesma empresa há menos de 1 ano. Foram observados diferentes cargos ou funções exercidas nas empresas entre os participantes da pesquisa, como também níveis hierárquicos organizacionais distintos, alguns aqui citados: técnicos, tecnólogos, assistentes, analistas, coordenadores, supervisores e gerentes.

Por fim, o tipo de atividade da empresa da grande maioria dos participantes da pesquisa se concentrou na área de Serviços, 78\% (35); a seguir, Comércio, 13\% (6); e Indústria, 9\% (4).

\section{b. Percepção do Processo de Recrutamento Interno e seus Critérios}

Foi questionado a respeito da percepção do Processo de Recrutamento Interno quanto aos seus critérios. Os resultados estão expressos nas tabelas abaixo:

Tabela 1: A empresa divulga as oportunidades internas existentes de forma clara para todos os colaboradores.

\begin{tabular}{lcc}
\hline \multicolumn{1}{c}{ Respostas dos participantes } & Frequência Absoluta & Frequência Percentual (\%) \\
\hline Discordo Totalmente & 3 & 7 \\
Discordo & 3 & 7 \\
Indeciso & 10 & 22 \\
Concordo & 15 & 33 \\
Concordo Plenamente & 14 & 31 \\
\multicolumn{1}{r}{ Total } & $\mathbf{4 5}$ & $\mathbf{1 0 0}$ \\
\hline
\end{tabular}

Fonte: Dados da pesquisa

Para esta afirmação, 64\% (29) dos respondentes concordam ou concordam plenamente com a citação, o que significa que a maioria tem acesso às informações referentes às vagas que são abertas internamente na empresa onde trabalham.

De acordo com as entrevistas feitas com profissionais da área de Recursos Humanos, as oportunidades internas são divulgadas através de correio eletrônico e também via comunicado impresso em quadro de aviso, facilitando, dessa maneira, a disseminação do Processo de Recrutamento Interno para todos os colaboradores interessados.

Tabela 2: Quando percebo que os critérios do Processo de Recrutamento Interno são justos, sinto-me motivado na empresa.

\begin{tabular}{lll}
\hline Respostas dos participantes & Frequência Absoluta & Frequência Percentual (\%) \\
\hline
\end{tabular}




\begin{tabular}{lcc} 
Discordo Totalmente & 0 & 0 \\
\hline Discordo & 1 & 2 \\
Indeciso & 4 & 9 \\
Concordo & 14 & 31 \\
Concordo Plenamente & 26 & 58 \\
\multicolumn{1}{r}{ Total } & $\mathbf{4 5}$ & $\mathbf{1 0 0}$ \\
\hline
\end{tabular}

Fonte: Dados da pesquisa

Tabela 3: Conhecer todas as etapas do Processo de Recrutamento Interno antes de participar me deixa mais interessado em me inscrever.

\begin{tabular}{lcc}
\hline \multicolumn{1}{c}{ Respostas dos participantes } & Frequência Absoluta & Frequência Percentual (\%) \\
\hline Discordo Totalmente & 0 & 0 \\
Discordo & 0 & 0 \\
Indeciso & 8 & 18 \\
Concordo & 10 & 22 \\
Concordo Plenamente & 27 & 60 \\
\multicolumn{1}{r}{ Total } & $\mathbf{4 5}$ & $\mathbf{1 0 0}$ \\
\hline
\end{tabular}

Fonte: Dados da pesquisa

De acordo com os dados mostrados na Tabela 2, a ampla maioria dos participantes da pesquisa - 89\% (40) - está de acordo de que deve haver um senso de justiça para os critérios de seleção dentro do Processo de Recrutamento Interno. Além disso, como se pode observar na Tabela 3, 82\% (37) dos respondentes afirmam que conhecer todas as etapas de um Processo de Recrutamento Interno faz com que os mesmos se sintam mais motivados em se inscrever.

Os interessados em participar de um recrutamento interno devem atender a requisitos mínimos, de acordo com a vaga para a qual se candidatam, como formação acadêmica compatível com a vaga, experiência profissional relevante na função desejada ou similar, além de conhecimentos técnicos indispensáveis para a posição, como o domínio de idiomas e informática. Os profissionais de Recursos Humanos entrevistados salientaram a avaliação de desempenho como sendo também um fator preponderante na escolha de um candidato para preenchimento de uma oportunidade interna. 
Tabela 4: Quando os reais motivos da escolha de um colaborador em uma seleção interna não são divulgados amplamente, acredito que houve privilégio de alguma maneira.

\begin{tabular}{lcc}
\hline \multicolumn{1}{c}{ Respostas dos participantes } & Frequência Absoluta & Frequência Percentual (\%) \\
\hline Discordo Totalmente & 0 & 0 \\
Discordo & 1 & 2 \\
Indeciso & 18 & 40 \\
Concordo & 11 & 24 \\
Concordo Plenamente & 15 & 34 \\
\multicolumn{1}{r}{ Total } & $\mathbf{4 5}$ & $\mathbf{1 0 0}$ \\
\hline
\end{tabular}

Fonte: Dados da pesquisa

Tabela 5: Quando não sou aprovado para um processo seletivo interno, questiono os critérios utilizados para a seleção.

\begin{tabular}{lcc}
\hline \multicolumn{1}{c}{ Respostas dos participantes } & Frequência Absoluta & Frequência Percentual (\%) \\
\hline Discordo Totalmente & 1 & 2 \\
Discordo & 4 & 9 \\
Indeciso & 22 & 49 \\
Concordo & 6 & 13 \\
Concordo Plenamente & 12 & 27 \\
\multicolumn{1}{r}{ Total } & $\mathbf{4 5}$ & $\mathbf{1 0 0}$ \\
\hline
\end{tabular}

Fonte: Dados da pesquisa

Quando os reais motivos da escolha de um colaborador em uma seleção interna não são transparentes ou divulgados pela organização, 58\% (26) dos respondentes acreditam haver favorecimento de alguma maneira, conforme dados apresentados na Tabela 4; entretanto, 49\% (22) estão indecisos quanto aos critérios utilizados para a seleção interna, que, se somados aos $11 \%$ (5) que se negam a questionar os métodos utilizados para a seleção, pode indicar algum grau de desinteresse em relação ao seu próprio desempenho durante todo o processo, segundo os dados apresentados na Tabela 5.

Para os profissionais entrevistados, a área de Recursos Humanos justifica a escolha de um colaborador para os demais candidatos preteridos à vaga no Processo de Recrutamento Interno, porém apenas quando questionada. Tal justificativa se dá através de um feedback (retorno) individual ao candidato, mencionando-se os fatores (técnicos e comportamentais) que pesaram favoravelmente ao escolhido. Finalmente, os entrevistados da área de Recursos Humanos afirmaram que também oferecem um retorno para direcionamento de carreira aos candidatos que não foram aprovados em um Processo de Recrutamento Interno. 


\section{c. Fatores de Sucesso ou Inibidores para o Processo de Recrutamento Interno}

Os respondentes da pesquisa foram indagados se já haviam participado de um Processo de Recrutamento Interno. Em caso afirmativo, eles eram direcionados a uma pergunta que versava sobre os fatores de sucesso para o Recrutamento Interno. Se a resposta fosse negativa, uma questão sobre os inibidores do Processo de Recrutamento Interno era apresentada ao questionário. De acordo com as respostas, 53\% (24) afirmaram já ter participado de um Processo de Recrutamento Interno. As Tabelas 6 e 7 mostram os dados relativos às duas perguntas. É importante notar que a soma da frequência percentual não é igual a $100 \%$, uma vez que os participantes da pesquisa podiam escolher até dois fatores de sucesso ou inibidores para o Processo de Recrutamento Interno.

Tabela 6: Fatores de Sucesso para o Processo de Recrutamento Interno - Caso você respondeu que já participou de um Processo de Recrutamento Interno, indique até 2 motivos que você considera os mais importantes, dentre os abaixo listados.

\begin{tabular}{lcc}
\hline \multicolumn{1}{c}{ Respostas dos participantes } & Frequência Absoluta & Frequência Percentual (\%) \\
\hline $\begin{array}{l}\text { Oportunidade de desenvolvimento } \\
\text { profissional }\end{array}$ & 21 & 88 \\
$\begin{array}{l}\text { Possibilidade de uma promoção na } \\
\text { empresa }\end{array}$ & 9 & 38 \\
$\begin{array}{l}\text { Perspectiva de mobilidade para } \\
\text { outras áreas/funções na empresa }\end{array}$ & 1 & 4 \\
\hline $\begin{array}{l}\text { Perspectiva de desenvolver novas } \\
\text { habilidades e competências }\end{array}$ & 21 & 88 \\
\hline Satisfação pessoal & 7 & 29 \\
\hline Outros & 0 & 0 \\
\hline
\end{tabular}

Fonte: Dados da pesquisa

Os participantes da pesquisa, quando indagados a respeito dos dois principais fatores de sucesso para o Processo de Recrutamento Interno, apontaram a "oportunidade de desenvolvimento profissional" e a "perspectiva de desenvolver novas habilidades e competências" como as respostas mais frequentes.

Pode-se observar que, apesar de itens como "possibilidade de uma promoção na empresa" e "perspectiva de mobilidade para outras áreas/funções na empresa" serem também um dos principais objetivos de um Processo de Recrutamento Interno, o resultado da pesquisa 
não confirmou esse argumento. Isso pode sugerir que, quando um profissional almeja mudar de área ou função ou objetiva um cargo superior ao atual, as oportunidades oferecidas no mercado de trabalho apresentam-se como mais práticas e atraentes do que o próprio Recrutamento Interno.

Outro dado interessante a ser observado é o item "satisfação pessoal", com apenas 7 votos. Isso pode explicar o fato de que o Recrutamento Interno em si não garante satisfação pessoal.

Tabela 7: Inibidores do Processo de Recrutamento Interno - Caso você respondeu que não participou de um Processo de Recrutamento Interno, indique até 2 motivos que você julga como os mais importantes, dentre os listados abaixo.

\begin{tabular}{lcc}
\hline \multicolumn{1}{c}{ Respostas dos participantes } & Frequência Absoluta & Frequência Percentual (\%) \\
\hline $\begin{array}{l}\text { Dificuldade em entender os } \\
\text { critérios para a participação no } \\
\text { Processo de Recrutamento Interno }\end{array}$ & 1 & 5 \\
$\begin{array}{l}\text { Possibilidade de sofrer algum tipo } \\
\text { de retaliação por parte da liderança } \\
\text { imediata }\end{array}$ & 9 & 43 \\
$\begin{array}{l}\text { Não ter o retorno adequado sobre } \\
\text { o meu desempenho após a } \\
\text { participação em um Processo de }\end{array}$ & 6 & 29 \\
Recrutamento Interno & & \\
$\begin{array}{l}\text { Caso não seja aprovado, posso } \\
\text { ficar com uma "imagem ruim" na } \\
\text { empresa }\end{array}$ & 5 & 24 \\
$\begin{array}{l}\text { Nunca me interessei em participar } \\
\text { de um Recrutamento Interno }\end{array}$ & 8 & 38 \\
\hline Outros & 5 & 24 \\
\hline
\end{tabular}

Fonte: Dados da pesquisa

No que tange aos fatores de inibição para o Processo de Recrutamento Interno, a frequência percentual ficou bastante equilibrada. Ter o apoio do superior imediato é uma razão preponderante quando da participação em um Processo de Recrutamento Interno, ou seja, sofrer alguma retaliação por parte da liderança imediata faz com que os colaboradores não se interessem pelo Recrutamento Interno, segundo os dados da pesquisa. Além disso, alguns participantes não se sentem à vontade em participar de um Recrutamento Interno por poderem ficar com uma "imagem negativa", caso não sejam aprovados no processo.

Pode-se também verificar a importância de um feedback (retorno) após a participação de um colaborador em um Processo de Recrutamento Interno. Este dado corrobora com os 
resultados apresentados na Tabela 4 - quando os resultados do processo não são amplamente divulgados, é possível questionar a lisura dos critérios de seleção - fazendo com que as pessoas envolvidas não se sintam confortáveis para participar de novos processos de recrutamento interno.

Para finalizar a análise da Tabela 7 e reforçar a percepção acerca da tabela anterior, a afirmação "nunca me interessei em participar de um Recrutamento Interno" pode ser um indicativo de que, apesar de todo o esforço despendido pela área de Recursos Humanos para promover e incentivar a adesão dos colaboradores aos processos seletivos internos, conforme entrevistas realizadas com os profissionais da área, muitos não acreditam que terão oportunidades de desenvolvimento profissional via Recrutamento Interno, optando, dessa maneira, por deixar a empresa atual e buscar novos desafios no mercado de trabalho.

\section{d. Percepção do Processo de Recrutamento Interno como Gerador de Satisfação no Ambiente de Trabalho}

Para esta categoria, os participantes da pesquisa foram indagados a respeito de várias perguntas relacionadas ao Processo de Recrutamento Interno como gerador de satisfação no ambiente profissional. Aqui são apontados os principais itens e as respectivas análises dos resultados.

Tabela 8: Acredito que o Recrutamento Interno é uma forma de proporcionar chances para que todos os colaboradores possam concorrer às oportunidades que surgem na empresa.

\begin{tabular}{lcc}
\hline \multicolumn{1}{c}{ Respostas dos participantes } & Frequência Absoluta & Frequência Percentual (\%) \\
\hline Discordo Totalmente & 0 & 0 \\
Discordo & 0 & 0 \\
Indeciso & 4 & 9 \\
Concordo & 13 & 29 \\
Concordo Plenamente $\quad$ Total & 28 & 62 \\
\multicolumn{1}{r}{$\quad \mathbf{4 5}$} & $\mathbf{1 0 0}$ \\
\hline
\end{tabular}

Fonte: Dados da pesquisa 
Tabela 9: Quando percebo que a empresa proporciona ferramentas como o Recrutamento Interno, sinto-me motivado pela possibilidade de crescimento profissional.

\begin{tabular}{lcc}
\hline \multicolumn{1}{c}{ Respostas dos participantes } & Frequência Absoluta & Frequência Percentual (\%) \\
\hline Discordo Totalmente & 0 & 0 \\
Discordo & 1 & 2 \\
Indeciso & 2 & 4 \\
Concordo & 15 & 34 \\
Concordo Plenamente & 27 & 60 \\
\multicolumn{1}{c}{ Total } & $\mathbf{4 5}$ & $\mathbf{1 0 0}$ \\
\hline
\end{tabular}

Fonte: Dados da pesquisa

Tabela 10: Acredito que o Recrutamento Interno pode contribuir para manter as pessoas com potencial e talento dentro da organização por mais tempo.

\begin{tabular}{lcc}
\hline \multicolumn{1}{c}{ Respostas dos participantes } & Frequência Absoluta & Frequência Percentual (\%) \\
\hline Discordo Totalmente & 0 & 0 \\
Discordo & 1 & 2 \\
Indeciso & 0 & 0 \\
Concordo & 17 & 38 \\
Concordo Plenamente & 27 & 60 \\
\multicolumn{1}{c}{ Total } & $\mathbf{4 5}$ & $\mathbf{1 0 0}$ \\
\hline
\end{tabular}

Fonte: Dados da pesquisa

Tabela 11: Acredito que o Recrutamento Interno pode aumentar a satisfação no ambiente de trabalho.

\begin{tabular}{lcc}
\hline \multicolumn{1}{c}{ Respostas dos participantes } & Frequência Absoluta & Frequência Percentual (\%) \\
\hline Discordo Totalmente & 0 & 0 \\
Discordo & 0 & 0 \\
Indeciso & 5 & 11 \\
Concordo & 13 & 29 \\
Concordo Plenamente $\quad$ Total & 27 & 60 \\
\multicolumn{1}{r}{$\quad \mathbf{4 5}$} & $\mathbf{1 0 0}$ \\
\hline
\end{tabular}

Fonte: Dados da pesquisa

Interessante observar que, na Tabela 8 , praticamente todos os participantes da pesquisa (91\%) consideram o Recrutamento Interno uma forma de proporcionar chances para que todos os colaboradores possam concorrer às oportunidades que surgem na empresa. Também é expressivo o índice (94\%) daqueles que se sentem motivados pela possibilidade de crescimento profissional através do Recrutamento Interno, conforme os dados mostrados na Tabela 9, evidenciando por que a área de Recursos Humanos o considera uma das principais ações para o gerenciamento de carreira dos colaboradores da organização. 
Quanto ao fato de que o Recrutamento Interno pode contribuir para reter os talentos da organização por mais tempo, $98 \%$ dos respondentes concordam ou concordam plenamente com esta afirmação, como indica a Tabela 10; e 89\% acreditam que o Recrutamento Interno pode aumentar a satisfação no ambiente de trabalho, segundo dados elucidativos da Tabela 11. Esses dados corroboram com as entrevistas realizadas com profissionais da área de Recursos Humanos, que, segundo eles, quando realizado de forma imparcial, aberta e contínua, o Recrutamento Interno pode não somente gerar oportunidades de carreira, mas também orientação para adequar o trajeto profissional de determinado colaborador que não está plenamente satisfeito com a atividade que exerce ou que deseja adquirir novos conhecimentos, podendo assim aumentar o tempo de permanência de um profissional na organização.

\section{e. Percepção do Processo de Recrutamento Interno como Fator Preponderante na Gestão de Carreira}

Os participantes da pesquisa foram questionados nesta categoria sobre a relação do Processo de Recrutamento Interno com o gerenciamento de suas carreiras. Também se destacam aqui os principais itens abordados e suas respectivas considerações e análises.

Tabela 12: Quando há um anúncio de uma oportunidade interna na empresa, observo atentamente aos requisitos solicitados para me desenvolver neles.

\begin{tabular}{|c|c|c|}
\hline Respostas dos participantes & Frequência Absoluta & Frequência Percentual (\%) \\
\hline Discordo Totalmente & 0 & 0 \\
\hline Discordo & 2 & 4 \\
\hline Indeciso & 3 & 7 \\
\hline Concordo & 16 & 36 \\
\hline Concordo Plenamente & 24 & 53 \\
\hline Total & 45 & 100 \\
\hline
\end{tabular}

Fonte: Dados da pesquisa 
Tabela 13: Receber feedback (retorno) após a participação em um Recrutamento Interno é fundamental, pois, dessa maneira, conhecerei os pontos nos quais preciso me desenvolver.

\begin{tabular}{lcc}
\hline \multicolumn{1}{c}{ Respostas dos participantes } & Frequência Absoluta & Frequência Percentual (\%) \\
\hline Discordo Totalmente & 0 & 0 \\
Discordo & 0 & 0 \\
Indeciso & 1 & 2 \\
Concordo & 14 & 31 \\
Concordo Plenamente & 30 & 67 \\
\multicolumn{1}{c}{ Total } & $\mathbf{4 5}$ & $\mathbf{1 0 0}$ \\
\hline
\end{tabular}

Fonte: Dados da pesquisa

Tabela 14: Sinto necessidade permanente de me desenvolver na empresa em que trabalho.

\begin{tabular}{lcc}
\hline \multicolumn{1}{c}{ Respostas dos participantes } & Frequência Absoluta & Frequência Percentual (\%) \\
\hline Discordo Totalmente & 0 & 0 \\
Discordo & 0 & 0 \\
Indeciso & 3 & 7 \\
Concordo & 10 & 22 \\
Concordo Plenamente $\quad$ Total & 32 & 71 \\
\multicolumn{2}{r}{$\quad \mathbf{4 5}$} & $\mathbf{1 0 0}$ \\
\hline
\end{tabular}

Fonte: Dados da pesquisa

Com relação à percepção do Processo de Recrutamento Interno como fator preponderante na gestão de carreira, pode-se aferir que $89 \%$ (40) dos participantes da pesquisa, de acordo com os resultados apresentados na Tabela 12, concordam ou concordam plenamente que, quando há um anúncio de uma oportunidade interna na empresa, os requisitos solicitados são atentamente considerados como forma de orientação para o desenvolvimento profissional. Quase a totalidade dos respondentes, 98\% (44) afirmam que receber feedback após a participação em um Recrutamento Interno é essencial, pois, dessa forma, os pontos a serem desenvolvidos/aprimorados serão conhecidos pelos candidatos, como é possível observar na Tabela 13. E 93\% (42) dos participantes da pesquisa acreditam que precisam se desenvolver constantemente na empresa atual, conforme números apresentados na Tabela 14.

Percebe-se pelas respostas que os participantes da pesquisa buscam aprimoramento de novas habilidades e competências de forma permanente, objetivando desenvolvimento profissional, fator este indicado também nos resultados apresentados na Tabela 6 deste trabalho. Outro ponto a ser levantado é o fato de que o Recrutamento Interno pode assumir um papel relevante na identificação de talentos já existentes na organização. Isso pode sugerir que as empresas precisam criar ferramentas que estimulem todo o potencial de seus

ReFAE - Revista da Faculdade de Administração e Economia, v. 8, n. 2, p. 37-59, 2017 
colaboradores, a fim de que eles possam permanecer na organização por mais tempo, fato crucial para o exercício da liderança, como apontaram Fernandes, Siqueira e Vieira (2014).

\section{CONSIDERAÇÕES FINAIS}

O objetivo principal do presente trabalho foi abordar o tema do Processo de Recrutamento e Seleção, com ênfase no Recrutamento Interno como gerador de desenvolvimento profissional, e como ele pode contribuir para a diminuição da rotatividade de pessoal nas empresas modernas.

Com relação aos critérios utilizados no Processo de Recrutamento Interno, verificou-se que, no geral, as oportunidades internas são amplamente divulgadas pela área de Recursos Humanos, ou seja, os candidatos que pleiteiam concorrer às vagas que são abertas internamente na empresa têm acesso às informações relativas ao processo como um todo.

O trabalho identificou que um senso de justiça para os critérios de seleção em um Processo de Recrutamento Interno é fator preponderante para que haja envolvimento dos candidatos interessados em concorrer a uma vaga interna. Acredita-se haver favorecimento de alguma maneira quando os reais motivos da escolha de um colaborador não são divulgados pela organização, porém não são feitos questionamentos com relação aos métodos utilizados para a seleção, o que pode evidenciar algum grau de desinteresse ou indiferença por parte dos candidatos durante todo o processo.

A área de Recursos Humanos, por sua vez, como o trabalho apontou, justifica a escolha de um colaborador para os demais candidatos preteridos à vaga interna apenas quando questionada, o que pode sugerir certa falta de transparência e comprometimento dos profissionais responsáveis por todo o gerenciamento do Recrutamento Interno.

No que tange aos fatores de sucesso e de inibição para o Processo de Recrutamento Interno, o trabalho revelou dados importantes. Os dois principais fatores de sucesso apontados foram "oportunidade de desenvolvimento profissional" e "perspectiva de desenvolver novas habilidades e competências", ambos muito à frente do item "satisfação pessoal", que, por sua vez, foi pouco lembrado pelos participantes da pesquisa. Isso pode indicar que o Recrutamento Interno em si não seja suficiente para garantir satisfação pessoal.

Já os principais inibidores do Processo de Recrutamento Interno tiveram frequência percentual equilibrada. A afirmação "nunca me interessei em participar de um Recrutamento Interno" foi votada com frequência, podendo ser um indicativo de que muitos colaboradores preferem deixar a empresa atual para buscar novos desafios no mercado de trabalho a 
participar de processos seletivos internos para alcançar novas oportunidades de desenvolvimento profissional.

Quando a pesquisa analisou a percepção do Processo de Recrutamento Interno como gerador de satisfação no ambiente de trabalho, pôde-se observar que o Recrutamento Interno proporciona chances para que todos os colaboradores possam concorrer às oportunidades que surgem na empresa. Além disso, de acordo com as entrevistas realizadas com profissionais da área de Recursos Humanos, o Recrutamento Interno pode aumentar o tempo de permanência de um profissional na organização quando assume um papel de orientação àquele que se sente insatisfeito com a função exercida na empresa ou que deseja ampliar seu horizonte de conhecimentos pela mobilidade para outras áreas/funções dentro da organização, desde que realizado de maneira transparente, neutra e permanente.

Analisou-se, por fim, o Processo de Recrutamento Interno e sua relação com a gestão de carreira. Quando há um anúncio de uma oportunidade interna na empresa, os requisitos solicitados são observados cuidadosamente como uma maneira de proporcionar desenvolvimento profissional, segundo os resultados da pesquisa mostraram. E atribuiu-se ao feedback, dado após a participação em um Recrutamento Interno, uma relativa importância no sentido de elucidar os pontos a serem aprimorados pelos postulantes a uma vaga interna.

Contudo, estudos posteriores se fazem necessários a fim de quantificar a possível retenção de profissionais com grande potencial nas organizações modernas por meio do Recrutamento Interno. Além disso, o tema mereceria estudos mais amplos e profundos com o objetivo de valorizar o capital humano, como a criação de bancos de talentos internos. 


\section{REFERÊNCIAS}

CAMPOS, V. F. O Valor dos Recursos Humanos na Era do Conhecimento. $7^{\mathrm{a}}$ ed. São Paulo: INDG, 2004.

CHIAVENATO, I. O Capital Humano das Organizações. $9^{a}$ ed. Rio de Janeiro: Elsevier Campus, 2009.

Gestão das Pessoas. $3^{\text {a }}$ ed. Rio de Janeiro: Elsevier - Campus, 2008a.

Planejamento, Recrutamento e Seleção de Pessoal: como agregar talentos à empresa. $7^{a}$ ed. São Paulo: Manole, 2008 b.

O Capital Humano das Organizações. $8^{\text {a }}$ ed. São Paulo: Atlas, 2006.

Treinamento e Desenvolvimento de Recursos Humanos. São Paulo: Atlas, 1999.

COSTA, L. V.; CHIUZI, R. M.; DUTRA, J. S. Relações entre percepção de sucesso na carreira e comprometimento organizacional: um estudo com professores do ensino superior de Administração. Revista de Administração da Unimep, v. 11, n. 2, p. 103-118, 2013.

COSTA, L. V.; DUTRA, J. Avaliação da carreira no mundo contemporâneo: proposta de um modelo de três dimensões. Revista de Carreiras e Pessoas, v. 1, n. 1, p. 1-22, 2011.

DESSLER, G. Administração de Recursos Humanos. São Paulo: P. Hall, 2003.

DUTRA, J. S. A Gestão de Carreira. Em FleuRY, M. T. L. (Org.) As Pessoas na Organização. São Paulo: Editora Gente, 2002.

Administração de Carreiras: uma proposta para repensar a gestão de pessoas. São Paulo: Atlas, 1996.

FERNANDES, C. M.; SIQUEIRA, M. M. M.; VIEIRA, A. M. Impacto da percepção de suporte organizacional sobre o comprometimento organizacional afetivo: o papel moderador da liderança. Revista Pensamento Contemporâneo em Administração, v. 8, n. 4, p. 140$162,2014$.

GATEWOOD, R. D.; FIELD, H.S. Human Resource Selection. Nova York: Harcourt Brace College, 1998.

GIANI, C. M. Recrutamento interno valorizando talentos. Disponível em http://www.aliceramos.com/rh/0009.asp. Acesso em 27 set. 2011, 10:18.

GUIMARÃES, M. F. O processo de recrutamento e seleção como uma ferramenta de gestão. Revista Ciências Empresariais da Unipar, Toledo, v. 6, n. 2, jul./dez., 2005.

JACKSON, T. Career Development. Bristol: Institute of Personnel and Development, 2000. 
OLIVEIRA, C. S. O recrutamento interno como fator motivacional. Trabalho de Conclusão de Curso (Administração de Empresas), Luziânia, Universidade Estadual de Goiás, 2009.

PONTES, B. R. Planejamento, Recrutamento e Seleção de Pessoal. $6^{\text {a }}$ ed. São Paulo: LTr, 2010.

A Arte de Selecionar Talentos. $1^{\text {a }}$ ed. São Paulo: DVS, 2005.

ROJAS, C. V. H. Banco de Talentos Interno: valorizando o capital humano. Disponível em http://www.artigonal.com/gestao-artigos/banco-de-talentos-interno. Acesso em 26 set. 2015, 09:40.

SILVA, M. L.; NUNES, G. S. Recrutamento e Seleção de Pessoal. $1^{a}$ ed. São Paulo: Érica, 2002.

VELOSO, E. F. R.; SCHIRMEISTER, R.; LIMONGI-FRANÇA, A. C. A influência da qualidade de vida no trabalho em situações de transição profissional: um estudo de caso sobre desligamento voluntário. Revista Administração e Diálogo, São Paulo, v. 9, n. 1, p. 35-58, 2007. 